\title{
Identificación y caracterización biológica del Barley yellow striate mosaic virus (BYSMV): Nueva enfermedad del trigo en Argentina
}

\author{
Analía D. Dumón ${ }^{1}$, Evangelina B. Argüello-Caro ${ }^{1}$, María V. Alemandri', Carlos Bainotti ${ }^{2}$, María F. Mattio ${ }^{1}$, \\ Sandra M. Rodríguez ${ }^{1}$, Mariana del $\operatorname{Vas}^{3}$ \& Graciela Truol ${ }^{1}$ \\ ${ }^{1}$ Instituto de Patología Vegetal, Instituto Nacional de Tecnología Agropecuaria, Córdoba, Argentina; ${ }^{2}$ Instituto Nacional \\ de Tecnología Agropecuaria, Estación Experimental Agropecuaria Marcos Juárez, Córdoba, Argentina; ${ }^{3}$ Instituto de \\ Biotecnología, Instituto Nacional de Tecnología Agropecuaria, Buenos Aires, Argentina
}

Autor para correspondencia: Analía D. Dumón, e-mail: analiadumon@yahoo.com.ar

\section{RESUMEN}

El cultivo de trigo (Triticum aestivum L.), es el cereal de invierno de mayor importancia económica en Argentina. Su producción se halla limitada por diversos factores, entre ellos las enfermedades virales. El objetivo del presente trabajo fue identificar y caracterizar biológicamente una enfermedad viral detectada recientemente en el cultivo de trigo en Argentina, que ha presentado elevada incidencia en los últimos años. Para ello, se recolectaron plantas con síntomas en localidades de: Miramar y Balcarce (Buenos Aires), Río Cuarto, Rosales y Marcos Juárez (Córdoba), Paraná (Entre Ríos) y General Pico (La Pampa) de la región triguera Argentina. Las muestras fueron caracterizadas a través de: microscopia electrónica ("leaf-dip" y cortes ultrafinos), serología (con antisueros para diferentes virosis del trigo por DAS-ELISA y ELISA indirecto), transmisión mecánica, por semilla y por vectores (delfácidos), rango de hospedantes diferenciales y susceptibilidad diferencial de diferentes cultivares de trigo en infecciones naturales. Los resultados obtenidos evidenciaron que esta nueva enfermedad es causada por el Barley yellow striate mosaic virus (BYSMV) (Rhabdoviridae-Cytorhabdovirus), un virus ampliamente distribuido a nivel mundial y que representa un riesgo potencial para otros cultivos como cebada, avena y triticale. Este trabajo representa el primer reporte del BYSMV en Argentina.

Palabras clave: Cytorhabdovirus, Delphacidae, Gramineae.

\begin{abstract}
Identification and biological characterization of Barley yellow striate mosaic virus (BYSMV): A new wheat disease in Argentina Wheat (Triticum aestivum L.) is the most important winter grain in Argentina. Its production is limited by several factors, including viral diseases. The aim of this study was to identify and characterize a recently detected disease of wheat crops in Argentina. Symptomatic plants were collected from different locations from the wheat production area, Miramar and Balcarce (Buenos Aires), Río Cuarto, Rosales and Marcos Juarez (Córdoba), Paraná (Entre Ríos) and General Pico (La Pampa). Samples were characterized by: electron microscopy (leaf-dip and ultrathin sections), serological tests (with antiserum reacting against different wheat viruses by DAS-ELISA and indirect ELISA), mechanical, seed and vector transmission assays, differential host range, and susceptibility of different wheat cultivars in natural infections. The results showed that this new disease is caused by Barley yellow striate mosaic virus (BYSMV) (RhabdoviridaeCytorhabdovirus), a widely distributed virus that can be transmitted to other crops such as barley, oat and triticale. This work represents the first report of BYSMV in Argentina.
\end{abstract}

Keywords: Cytorhabdovirus, Delphacidae, Gramineae.

\section{INTRODUCCIÓN}

La producción mundial de trigo (Triticum aestivum L.) representa el $30 \%$ de la producción total de granos, siendo la base de la alimentación de todo el mundo. El 90\% de las exportaciones mundiales de trigo está representado por la producción de Estados Unidos, Canadá, la Unión Europea, Sur de Asia, Australia y Argentina (USDA, 2011).

El cultivo de trigo representa el cereal de invierno de mayor importancia económica en Argentina, tanto por la superficie sembrada (3,6 millones de ha) como por el volumen de producción (11 millones de toneladas)
(PRECOPINTA, 2011). Las áreas de mayor producción se encuentran en el sur de la provincia de Buenos Aires y en el norte de la región pampeana húmeda. Aunque en menor escala, también se siembra en el noreste y noroeste del país (MAGYP, 2011).

El rendimiento del cultivo se ve limitado por diversos factores, entre ellos las enfermedades virales. A nivel mundial, las virosis que causan mayores pérdidas son Barley yellow dwarf virus (BYDV), Wheat streak mosaic virus (WSMV), Wheat spindle streak mosaic virus (WSSMV) y Soil-borne wheat mosaic virus (SBWMV). En Argentina, hasta el año 2005 se habían detectado BYDV 
(BYDV-PAV, BYDV-MAV; BYDV-SGV, BYDV-RMV), Cereal yellow dwarf virus (CYDV-RPV), WSMV, Barley stripe mosaic virus (BSMV), Mal de Río Cuarto virus (MRCV), y SBWMV. Estas enfermedades se presentan con mayor o menor incidencia en diferentes localidades de la región triguera argentina, tanto en infecciones simples como mixtas, en diferentes combinaciones dependiendo de la presencia de, factores ambientales, momento de la infección, vectores y cultivares afectados (Truol, 2009).

En el año 2006, se observó una nueva sintomatología en lotes de trigo de las provincias de Buenos Aires, Córdoba, Entre Ríos y La Pampa. Dichos cultivos mostraron marcadas y severas estrías cloróticas, enanismo, arrosetamiento, espigas vanas amarillentas, sumado a una severa disminución en el rendimiento (con pérdidas aproximadas del 80\%). Estas características sugirieron la presencia de una nueva enfermedad del trigo aún no detectada en la Argentina (Sagadin et al., 2007). Actualmente, en el 2011, en lotes de trigo cv. Biointa 3005 se ha observado una incidencia del $40 \%$ en la localidad de Cannals (Córdoba). Estudios preliminares mediante microscopía electrónica evidenciaron que esta sintomatología estaba causada por un virus baciliforme característico de la familia Rhabdoviridae (Truol et al., 2008), siendo necesaria la identificación y caracterización biológica de la enfermedad.

Los fitorhabdovirus se dividen en dos grandes grupos: Cytorhabdovirus, que replican en el citoplasma de las células de las plantas y Nucleorhabdovirus cuya replicación ocurre en el núcleo (Tordo et al., 2005; Mayo \& Pringle, 1998). Sin embargo, recientemente se encontró otro tipo de rhabdovirus, de genoma bipartido y transmitido por ácaros Brevipalpus, al cual se ha asignado un nuevo género, Dichorhabdovirus (Kondo et al., 2006). Entre las enfermedades virales del trigo causadas por rhabdovirus se encuentran Cytorhabdovirus tales como Barley yellow striate mosaic virus, Wheat American striate mosaic virus, Northern cereal mosaic virus, Winter wheat Russian mosaic virus y Nucleorhabdovirus tales como Cereal chlorotic mottle virus, entre otros (Jackson et al., 2005).

Las enfermedades causadas por rhabdovirus de trigo se caracterizan por producir mosaicos en las hojas, disminución del crecimiento y formación de espigas vanas (Shtein-Margolina, 2002). Los rhabdovirus no se transmiten por semillas y la mayoría no son fácilmente transmitidos mecánicamente (Hogenhout et al., 2003; Hogenhout et al., 2008). Todos ellos son transmitidos por insectos, principalmente áfidos, cicadélidos y delfácidos (Hemiptera: Sternorryncha y Auchenorryncha). La transmisión por insectos es altamente específica dado que una especie de virus es transmitida por una o pocas especies relacionadas de insectos (Falk \& Tsai, 1985; Redinbaugh et al., 2002). Por otra parte los insectos no sólo actúan como vectores sino que también son hospedantes para la replicación viral, constituyendo así una importante fuente de reservorio del virus.

El objetivo del presente estudio fue identificar y caracterizar biológicamente el Barley yellow striate mosaic virus (BYSMV) recientemente detectado en cultivos de trigo en Argentina.

\section{MATERIALES Y MÉTODOS}

Recolección de plantas sintomáticas de diferentes localidades del área triguera Argentina

Se realizaron recolecciones en lotes de trigo (tres muestras por localidad) que presentaban síntomas de mosaico estriado y espigas amarillas y vanas (Figura 1), en las provincias de Buenos Aires (Miramar y Balcarce), Córdoba (Río Cuarto Marcos Juárez y Rosales), Entre Ríos

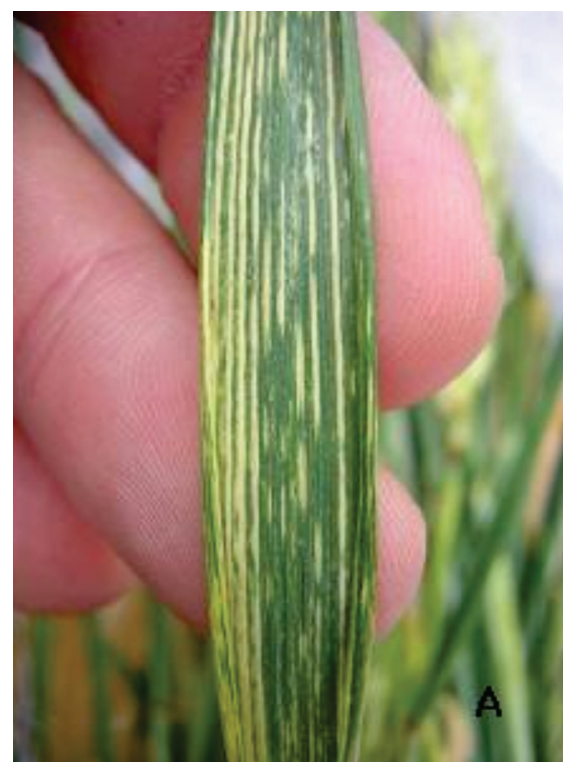

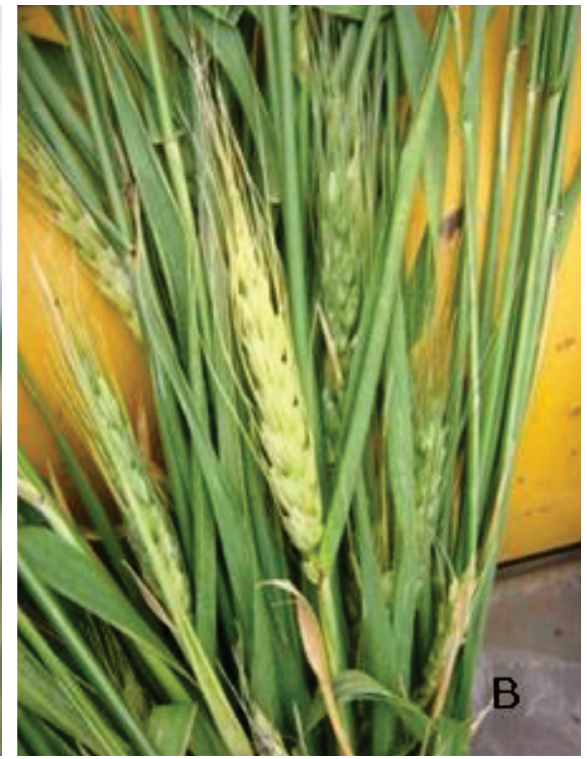

FIGURA 1 - Síntomas de Barley yellow striate mosaic virus en trigo infectado naturalmente. A. síntoma de estrías cloróticas en la hoja bandera; B. síntoma de espiga amarilla en plantas enfermas. 
(Paraná), La Pampa (General Pico). Se recolectaron hojas sintomáticas en plantas al estadío de hoja bandera. Las distintas muestras fueron analizadas a través de serología y microscopía electrónica como se describe a continuación.

\section{Análisis serológico}

Para el análisis serológico se emplearon antisueros específicos (Agdia Inc., USA) contra BYDV (BYDVPAV, BYDV-MAV, BYDV-SGV, BYDV-RMV), CYDVRPV, WSMV, Maize mosaic virus (MMV), mediante la aplicación de la técnica DAS-ELISA (Truol et al., 2009). Para la detección de BSMV (Agdia Inc., USA) y BYSMV se realizó ELISA indirecto (Conci, 1999) utilizando para esta última virosis un antisuero gentilmente provisto por el Dr. Conti; Laboratorio de Fitovirología Aplicada (Torino, Italia). Las muestras fueron maceradas en tampón de extracción en una relación 1/10 (P/V). Una vez concluida las reacciones se obtuvieron las absorbencias a $405 \mathrm{~nm}$ $\left(\mathrm{A}_{405}\right)$ mediante un lector de ELISA (Kayto RT-2100 C). Se consideraron enfermas las muestras que superaron el límite de corte obtenido por la sumatoria de la media de los testigos sanos más tres veces el desvío estándar.

\section{Microscopía electrónica}

Se realizaron preparados de "leaf-dip" según el protocolo propuesto por Truol et al., 2009, utilizando acetato de uranilo como contrastante. Para los estudios citopatológicos se fijaron trozos de hojas sintomáticas de trigo recolectadas a campo, de $1 \mathrm{~mm}$ de longitud, en mezcla de glutaraldehído paraformaldehído seguido de postosmicación (se fijaron tres muestras por localidad). Luego se incluyeron en resina Spurr (Truol et al., 2009). Los cortes ultrafinos se tiñeron con acetato de uranilo al $2 \%$ y citrato de plomo y posteriormente se observaron al Microscopio Electrónico JEOL 1200 EX a una magnificación de $10.000 \mathrm{X}$.

\section{Transmisión mecánica}

Se tomaron hojas sintomáticas de trigo provenientes de la localidad de Río Cuarto (Córdoba) y se maceraron en tampón fosfato de sodio $0,01 \mathrm{M}$ (relación $1 / 5 \mathrm{P} / \mathrm{V} ; \mathrm{pH}$ 7,4). Con este extracto, se inocularon 30 plantas de trigo cv. Baguette 10 con dos hojas desarrolladas. Posteriormente las plantas se ubicaron en invernáculo, bajo condiciones controladas $\left(\mathrm{T}^{\circ} 23+2^{\circ} \mathrm{C}\right)$. A los 15 días post inoculación se tomaron muestras de las plantas inoculadas y se analizaron por serología (ELISA indirecto, anti BYSMV).

\section{Transmisión por vectores}

Transmisión Experimental: Se evaluó la capacidad vectora para esta nueva enfermedad viral (aislamiento Río Cuarto, Córdoba) de cuatro especies de delfácidos, Chionomus haywardi (Muir), Delphacodes kuscheli Fennah, Pyrophagus tigrinus Remes Lenicov \& Varela y Toya propinqua (Fieber), frecuentemente encontrados en campos de trigo de la región triguera Argentina. Se partió de poblaciones sanas mantenidas en cría en el Laboratorio de Vectores de IFFIVE-INTA, bajo condiciones controladas de temperatura $\left(23+2{ }^{\circ} \mathrm{C}\right), \mathrm{HR}(50 \%)$ y fotoperíodo $(16 \mathrm{~L}: 8 \mathrm{D})$ (Truol et al., 2001). Se tomaron 50 ninfas de segundo estadío de desarrollo de cada especie y se colocaron sobre plantas de trigo sintomáticas para el rhabdovirus (aislamiento Río Cuarto) durante $48 \mathrm{~h}$ para que adquieran el virus (período de adquisición, PA). Al cabo de este período, los insectos fueron transferidos a plantas de trigo sanas para cumplir el período de latencia (PL) de 10 días. Transcurrido este tiempo, subgrupos de 5 delfácidos se colocaron a transmitir sobre plántulas sanas (presión de inoculo de cinco insectos/ planta) de trigo cv. Baguette 10, cebada (Hordeum vulgare L. cv. Goldie), avena (Avena sativa L. cv. Bonaerense Payé) y triticale (Triticum x Secale cv. Genú) durante 24 h. Transcurrido este lapso se separaron los insectos y las plantas fueron colocadas bajo condiciones de invernáculo hasta el desarrollo de síntomas. Posteriormente se controlaron por serología (ELISA indirecto).

Transmisión Natural: Durante las campañas 2009/2010 se realizaron muestreos en la localidad de Río Cuarto, en campos de avena, cebada y trigo que presentaban síntomas de la enfermedad causada por el rhabdovirus. Se recolectaron 75 ejemplares de delfácidos mediante red entomológica de arrastre, en la zona de Río Cuarto (Córdoba). Estos insectos fueron clasificados bajo lupa utilizando la clave taxonómica propuestas por Remes Lenicov \& Virla, 1999) Cada ejemplar fue colocado individualmente sobre una plántula sana de cebada cv. Goldie, durante $48 \mathrm{~h}$. Este cereal se prefiere para realizar las transmisiones debido a su susceptibilidad y a la temprana expresión de los síntomas. Las plantas fueron observadas diariamente hasta que evidenciaron los síntomas de la enfermedad y se corroboraron por serología (ELISA indirecto).

\section{Transmisión por semillas}

Se emplearon semillas de trigo de los cultivares Klein Guerrero y Baguette 21 provenientes de lotes infectados naturalmente en la localidad de Miramar (Buenos Aires). Las semillas provenientes de estos lotes fueron cosechadas y sembradas sobre bandejas plásticas de $40 \mathrm{~cm} \times 60 \mathrm{~cm}$, en surcos, separadas por aproximadamente dos centímetros entre sí. Las plantas emergidas se mantuvieron en invernáculo hasta el estadío de hoja bandera. Se evaluaron 832 plantas del cultivar Klein Guerrero y 826 plantas del cultivar Baguette 21. La transmisión del virus se determinó mediante observación de síntomas y posterior corroboración por serología.

\section{Aislamiento y multiplicación de inóculos}

Para el aislamiento y multiplicación de inóculos del rhabdovirus se empleó $D$. kuscheli como vector, el cual se mostrara capaz de transmitir el virus. Se multiplicaron tres aislamientos del virus proveniente de plantas de trigo 
enfermas de las localidades de Miramar (Buenos Aires), Río Cuarto y Rosales (Córdoba) en cebada cv. Goldie y avena cv. Bonaerense Payé. Para las transmisiones se emplearon tiempos de Adquisición de $48 \mathrm{~h}$ (PA), de Latencia de 10 días (PL) y de Transmisión de 24 h (PI) (modificado de Conti, 1980).

Las plantas transmitidas de los tres aislamientos del virus se mantuvieron en invernáculo hasta la aparición de síntomas; posteriormente se confirmó la presencia de virus por ELISA.

\section{Patogenicidad de los inóculos}

Se evaluó la patogenicidad de tres aislamientos Miramar, Río Cuarto y Rosales, según la severidad de síntomas y el porcentaje de incidencia. Para la transmisión se utilizaron ninfas de segundo estadío de D. kuscheli. Los insectos se colocaron sobre plantas de avena enfermas durante $48 \mathrm{~h}$ y posteriormente se pasaron a plantas de trigo sanas, hasta transcurrir el período de latencia de 10 días. Luego, se colocaron a transmitir durante $24 \mathrm{~h}$ sobre cebada, cv Goldie. Se realizaron cinco repeticiones de 20 plantas para cada caso, con una presión de inóculo de cinco insectos por planta. Una vez transmitidas, las plántulas se colocaron en invernáculo hasta la aparición de síntomas. Posteriormente se evaluó la patogenicidad de los inóculos mediante el registro de la severidad de síntomas y la incidencia mediante serología y ANOVA.

\section{Rango de hospedantes diferenciales y sintomatología}

Para evaluar el rango de especies hospedantes diferenciales de esta nueva enfermedad, se inocularon plantas de cebada cv. Goldie, avena cv. Bonaerense Payé, trigo cv. Pro INTA Federal y triticale cv. Genú con insectos infectivos para el virus. Para cada especie se utilizaron 30 plantas.

Los ensayos de transmisión se realizaron como fue descripto para el punto anterior (utilizando sólo el aislamiento Río Cuarto). Todas las plantas utilizadas fueron analizadas por sintomatología y serología.

\section{Malezas y especies reservorio de la enfermedad}

Se recolectaron diferentes especies de gramíneas aledañas a lotes de trigo, avena y cebada que presentaban síntomas de estriado, amarillamiento, enanismo y arrosetamiento en las localidades de Miramar (Buenos Aires) y Río Cuarto (Córdoba). Se recolectaron plantas u hojas de cebadilla criolla (Bromus catharticus Vahl.), sorgo (Sorghum sp), moha (Setaria italica (L) P. Beauv.), centeno (Secale cereale (L.) M. Bieb.), cebada (Hordeum vulgare L.) y avena (Avena sativa L.). Las muestras fueron analizadas por serología para determinar la presencia de la virosis.

\section{Susceptibilidad de cultivares en infecciones naturales}

Se realizó un ensayo para evaluar el comportamiento de diferentes cultivares de trigo pan (con distintos ciclos vegetativos-reproductivos) frente a la infección natural del virus en el vivero de verano del Programa de Mejoramiento de trigo del INTA. El ensayo se llevó a cabo en la Chacra Experimental Miramar $\left(38^{\circ} 10^{\prime} \mathrm{S} 58^{\circ} 0^{\prime} \mathrm{W}\right)$, la cual es un ambiente propicio para la ocurrencia de epifitias por virus, inclusive debido a la presencia de hospedantes alternativos como malezas, trigos "guachos" y pasturas. Para el estudio, se usó un diseño de ensayo Alfa para el control espacial de filas y columnas. El tamaño de la parcela fue de siete surcos de $20 \mathrm{~cm}$ x $5 \mathrm{~cm}$ de largo para cada cultivar y se sembraron a densidades: 300 plantas $/ \mathrm{m}^{2}$ (normal) y 150 plantas $/ \mathrm{m}^{2}$ (baja). Se estimó la incidencia y severidad de síntomas del virus en estado 7 de la escala Zadoks (Zadoks et al., 1974) para cada cultivar y densidad de siembra. Los cultivares fueron clasificados en clases de severidad según: $\mathrm{R}=0 \%$ de plantas afectadas; $\mathrm{MR}=5-20 \%$ de plantas afectadas; $\mathrm{MS}=20-40 \%$ de plantas afectadas y $\mathrm{S}=40-100 \%$ de plantas afectadas. Para evaluar la incidencia se utilizó una escala de 0-9.

Para detectar la presencia del virus, se hicieron muestreos dirigidos en cada parcela, de plantas con síntomas de estrías cloróticas, enanismo, espigas amarillas y vanas. La sintomatología se confirmó a través de serología.

\section{RESULTADOS}

\section{Análisis serológico}

El $100 \%$ de las muestras de trigo provenientes de las localidades estudiadas: Miramar, Balcarce, Río Cuarto, Marcos Juárez, Rosales, General Pico y Paraná, resultaron positivas para BYSMV. Los análisis serológicos aplicados sobre dichas muestras para la detección de BYDV (BYDVPAV, BYDV-MAV, BYDV-SGV, BYDV-RMV), CYDV, WSMV, MMV y BSMV resultaron negativos. Los valores medios de absorbancia de las muestras enfermas se muestran en la Tabla 1, considerándose positivos aquellos que superaron la media de los testigos sanos más tres veces el desvío estándar.

\section{Microscopía electrónica}

Tanto la técnica de "leaf-dip" como los cortes ultrafinos observados al Microscopio Electrónico evidenciaron la presencia de partículas virales del tipo baciliformes (300nm de longitud $\times 60-70 \mathrm{~nm}$ de largo), típicas de los rhabdovirus. En los cortes ultrafinos las

TABLA 1 - Resultado del análisis por serología (ELISA-indirecto) para BYSMV, realizado sobre plantas de campo provenientes de distintas localidades

\begin{tabular}{lcc}
\hline \hline Localidad & $\begin{array}{c}\text { Absorbancia } \\
\text { media }\end{array}$ & $\begin{array}{c}\text { Límite de } \\
\text { corte }\end{array}$ \\
\hline Miramar & 1,246 & 0,184 \\
Balcarce & 1,443 & 0,132 \\
Río Cuarto & 1,557 & 0,184 \\
Marcos Juárez & 1,034 & 0,205 \\
Rosales & 0,824 & 0,108 \\
Paraná & 0,928 & 0,380 \\
General Pico & 2,112 & 0,380 \\
\hline
\end{tabular}


partículas se observaron en el citoplasma de las células parenquimáticas del floema contenidas en el lumen del retículo endoplásmico (Figura 2) y comúnmente una masa fibrosa que correspondería al viroplasma. No se observaron viriones en el núcleo de las células.

\section{Transmisión mecánica}

El virus no pudo transmitirse mecánicamente. Del total de 30 plantas inoculadas, ninguna presentó síntomas de BYSMV ni resultó positiva por serología.

\section{Transmisión por vectores}

Transmisión experimental: Se logró la transmisión experimental del aislamiento Río Cuarto del BYSMV con las cuatro especies de delfácidos evaluadas, D. kuscheli (eficiencia de transmisión del 80\%), Ch. haywardi (eficiencia de transmisión del 60\%), P. tigrinus (eficiencia

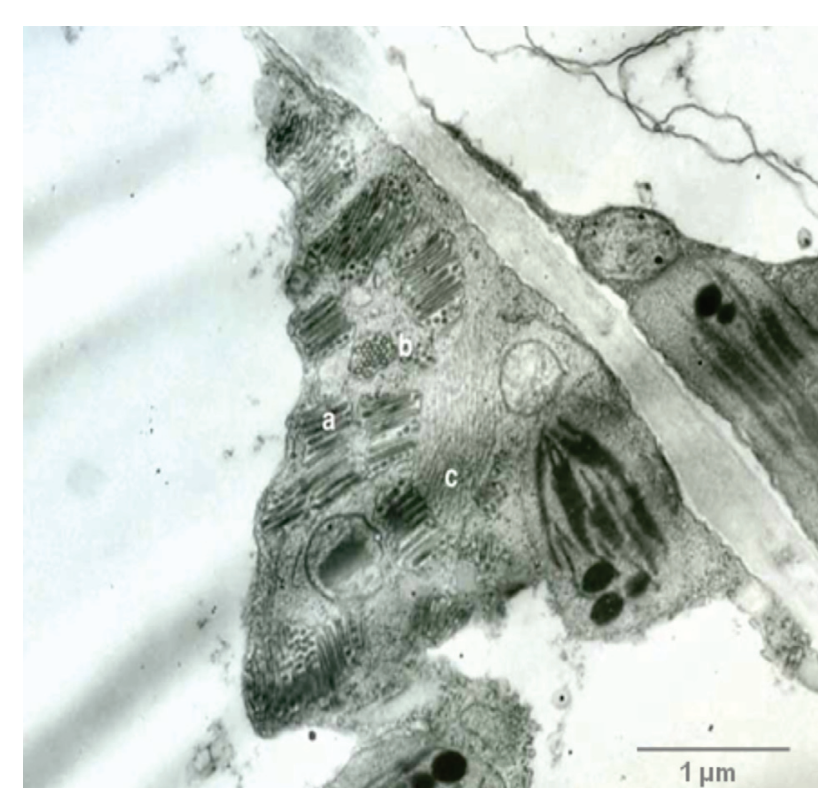

de transmisión del 35\%) y T. propinqua (eficiencia de transmisión de 45\%). Entre los síntomas más evidentes que mostraron las plantas transmitidas se observó presencia de estriado a lo largo de la lámina foliar, arrosetamiento, enanismo y espigas vanas (Figura 3). La transmisión fue confirmada por serología.

Transmisión natural: de los 75 delfácidos recolectados en lotes de la localidad de Río Cuarto, 68 fueron identificados como D. kuscheli, tres como P. tigrinus, dos como $T$. propinqua y dos como C. haywardi. Del total de plantas de cebada evaluadas en las transmisiones llevadas a cabo por estas especies, tres plantas resultaron positivas para BYSMV por ELISA indirecto. Dichas plantas correspondieron a las transmitidas por D. kuscheli y mostraron estrías cloróticas, amarillamiento de las hojas, enanismo y arrosetamiento, característico de los síntomas de la enfermedad encontrada a campo.

FIGURA 2 - Observación al microscopio electrónico de cortes ultrafinos e identificación de partículas virales baciliformes en el citoplasma de las células en relación a membranas del Retículo Endoplasmático. A. partículas virales agregadas dispuestas longitudinalmente; B. corte transversal; C. material fibrilar en el viroplasma.
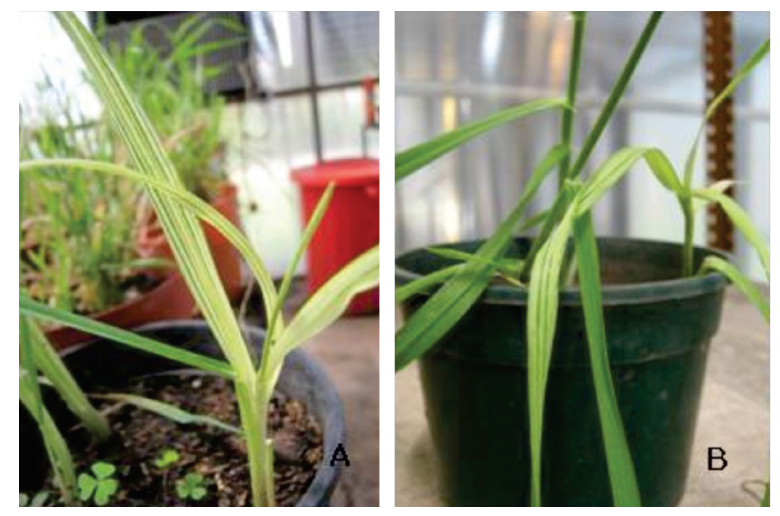

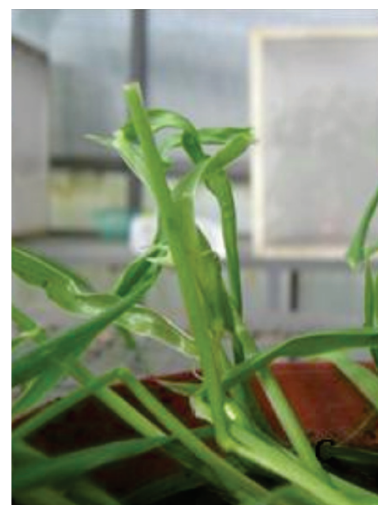

FIGURA 3 - Síntomas de Barley yellow striate mosaic virus en plantas infectadas experimentalmente con Delphacodes kuscheli. A. planta de trigo cv. ProINTA Federal en donde se observan estrías cloróticas similares a las observadas a campo; B. planta de cebada cv. Goldie mostrando estriado en las hojas; C. planta de avena cv. Bonaerense Payé con retorcimiento de tallos y hojas. 


\section{Transmisión por semillas}

Ninguna de las plantas emergidas a partir de semillas de trigo de los cultivares Baguette $21(\mathrm{n}=826)$ y Klein Guerrero $(\mathrm{n}=832)$ mostraron síntomas de BYSMV ni resultaron positivos por ELISA, concluyéndose por lo tanto que este virus no se transmite por semilla.

\section{Aislamiento y multiplicación del inóculo}

Se lograron multiplicar tres aislamientos del virus en cebada y avena: aislamiento Río Cuarto, aislamiento Rosales (Córdoba) y aislamiento Miramar (Buenos Aires). Las plantas transmitidas evidenciaron síntomas de estriado, amarillamiento y espigas vanas. Los tiempos de Adquisición (PA) de 48 hs., de Latencia (PL) de 10 días y de Transmisión (PI) de 24 hs. propuestos según la bibliografía consultada previamente (Conti, 1980) resultaron exitosos para la transmisión experimental con delfácidos. Los resultados fueron confirmados por serología.

\section{Patogenicidad de los inóculos}

La evaluación de síntomas según aislamiento en cebada cv. Goldie, mostró que no hubo diferencias en la sintomatología expresada y tampoco en el tiempo de aparición de los síntomas (10 días post-inoculación). Las plantas enfermas presentaron un marcado enanismo, estrías cloróticas y ninguna de ellas llegó al estado reproductivo. Se obtuvieron porcentajes de infección del 35\%, 33\% y $31,2 \%$ para los aislamientos de Miramar, Río Cuarto y Rosales, respectivamente, aunque estas diferencias en la incidencia de la enfermedad no resultaron estadísticamente significativas $(P=0.95)$.

\section{Rango de hospedantes diferenciales y sintomatología}

Las cuatro especies de cereales (avena, cebada, trigo y triticale) transmitidas experimentalmente con el virus, aislamiento Río Cuarto, por ejemplares infectivos de $D$. kuscheli evidenciaron los síntomas característicos de la enfermedad y resultaron seropositivas para BYSMV. El grado de expresión de los síntomas varió entre las especies evaluadas. La cebada (Figura 3B) y el trigo (Figura 3A) mostraron un mayor estriado de las hojas, mientras que en avena y triticale este síntoma fue más leve. La aparición de espigas vanas amarillas y arrosetamiento se observó en todas las plantas analizadas. Por otro lado, la avena fue la única especie que presentó un severo retorcimiento de tallos y hojas (Figura 3C).

\section{Malezas y especies reservorio de la enfermedad}

Los análisis serológicos evidenciaron la presencia de BYSMV en las muestras de cebada, avena, sorgo y cebadilla criolla colectadas a campo. El virus no fue detectado en moha ni en centeno, provenientes de las localidades de Miramar y Río Cuarto.

\section{Susceptibilidad de cultivares en infecciones naturales}

Los resultados de la evaluación de cultivares de trigo en infecciones naturales se detallan en la Tabla 2.
Los cultivares Baguette 21, Baguette Premium 11 y Buck Guapo resultaron con mayor susceptibilidad a la infección por BYSMV, ocurriendo la muerte de la planta en estado de macollaje. Por otro lado, el cultivar Buck 75 Aniversario mostró un mejor comportamiento ante la enfermedad, siendo el único cultivar que se comportó como moderadamente resistente. Por otra parte, no se registró la presencia de otras virosis.

Con respecto a la densidad de siembra, no se observaron diferencias de incidencia y daño ocasionado.

\section{DISCUSIÓN}

Las pruebas desarrolladas en este trabajo que incluyen análisis serológico, microscopía electrónica, rango de hospedantes, transmisión por semilla, transmisión mecánica y por vector, permitieron detectar por primera vez la presencia de Barley yellow striate mosaic virus (BYSMV) (Rhabdoviridae: Cytorhabdovirus) para el cultivo de trigo en Argentina, como así también caracterizar y determinar las principales características biológicas de este virus. Este reporte resulta de gran importancia por ser la primer mención en el país y ya que esta nueva enfermedad puede afectar severamente el cultivo de trigo, tal como aconteció en el 2006. Durante dicha campaña esta enfermedad atrajo la atención tanto de los productores como de los investigadores por su alta incidencia y la disminución en la productividad del cultivo, observándose valores de incidencia de hasta el $100 \%$ y lotes con pérdidas totales (Sagadin et al., 2007). Esta virosis ha sido descripta principalmente en cereales de Estados Unidos, Francia, Italia, China, Japón, Rusia y otros países (Conti \& Plumb, 1977; Milne et al., 1986; Minskaya et al., 1987), afectando los cultivos de trigo y cebada.

Las observaciones al Microscopio Electrónico concuerdan con las características y morfología de las partículas virales descriptas para la Familia Rhabdoviridae, del género Cytorhabdovirus (Jackson et al., 2005). De este modo, el largo de las partículas observado en las secciones ultrafinas se corresponde con los reportes de otros autores (Milne \& Conti, 1986, Milne et al., 1986; Lockhart et al., 1986) para BYSMV.

La falta de transmisión mecánica y por semilla para este virus también se corresponde con lo obtenido por Conti (1980) para BYSMV en Torino (Italia), donde no se logró la transmisión mecánica y no se detectó el virus en plántulas de trigo cv. Mara, emergidas a partir de semillas de plantas infectadas naturalmente con la virosis.

El aislamiento Río Cuarto de BYSMV fue transmitido experimentalmente por los delfácidos D. kuscheli, $T$. propinqua, Ch. haywardi y P. tigrinus, del mismo modo en que lo hacen otros rhabdovirus de plantas (Hogenhout et al., 2003; Jackson et al., 2005). Lockhart et al., 1986 también reportaron a $T$. propinqua como vector experimental de BYSMV en Morocco donde esta especie se presenta en gran abundancia en los cultivos de cereales. En Argentina, en cambio, $T$. propinqua se encuentra comúnmente sobre 
TABLA 2 - Evaluación de cultivares de trigo pan a la infección natural por BYSMV en el vivero de verano en la Chacra Experimental Miramar (MAA)

\begin{tabular}{|c|c|c|c|c|}
\hline Materiales & Ciclos & Densidad & Severidad & Incidencia \\
\hline ACA 901 & $\mathrm{C}$ & NORMAL & MSMR & 4 \\
\hline ACA 901 & $\mathrm{C}$ & BAJA & MSMR & 4 \\
\hline BAGUETTE 17 & $\mathrm{~L}$ & NORMAL & MS & 3 \\
\hline BAGUETTE 17 & $\mathrm{~L}$ & BAJA & MS & 3 \\
\hline BAGUETTE 21 & $\mathrm{~L}$ & NORMAL & $\mathrm{S}$ & 9 \\
\hline BAGUETTE 21 & $\mathrm{~L}$ & BAJA & $\mathrm{S}$ & 9 \\
\hline BAGUETTE 9 & $\mathrm{C}$ & NORMAL & $\mathrm{S}$ & 3 \\
\hline BAGUETTE 9 & $\mathrm{C}$ & BAJA & $\mathrm{S}$ & 3 \\
\hline BAGUETTE PREMIUM 11 & $\mathrm{~L}$ & NORMAL & $\mathrm{S}$ & 8 \\
\hline BAGUETTE PREMIUM 11 & $\mathrm{~L}$ & BAJA & $\mathrm{S}$ & 8 \\
\hline BIOINTA 1002 & $\mathrm{C}$ & NORMAL & $\mathrm{S}$ & 8 \\
\hline BIOINTA 1002 & $\mathrm{C}$ & BAJA & $\mathrm{S}$ & 8 \\
\hline BIOINTA 1006 & $\mathrm{C}$ & NORMAL & MSMR & 4 \\
\hline BIOINTA 1006 & $\mathrm{C}$ & BAJA & MSMR & 4 \\
\hline BIOINTA 2004 & $\mathrm{~L}$ & NORMAL & NO ESPIGÓ & - \\
\hline BIOINTA 2004 & $\mathrm{~L}$ & BAJA & NO ESPIGÓ & - \\
\hline BUCK 75 ANIVERSARIO & $\mathrm{C}$ & NORMAL & MR & 4 \\
\hline BUCK 75 ANIVERSARIO & $\mathrm{C}$ & BAJA & MR & 4 \\
\hline BUCK BAQUEANO & $\mathrm{L}$ & NORMAL & $\mathrm{S}$ & 6 \\
\hline BUCK BAQUEANO & $\mathrm{L}$ & BAJA & $\mathrm{S}$ & 6 \\
\hline BUCK GUAPO & $\mathrm{L}$ & NORMAL & $\mathrm{S}$ & 9 \\
\hline BUCK GUAPO & $\mathrm{L}$ & BAJA & $\mathrm{S}$ & 9 \\
\hline KLEIN GUERRERO & $\mathrm{L}$ & NORMAL & MSMR & 4 \\
\hline KLEIN GUERRERO & $\mathrm{L}$ & BAJA & MSMR & 4 \\
\hline KLEIN TIGRE & $\mathrm{C}$ & NORMAL & MSMR & 4 \\
\hline KLEIN TIGRE & $\mathrm{C}$ & BAJA & MSMR & 4 \\
\hline BIOINTA 1005 & $\mathrm{C}$ & NORMAL & MSMR & 1 \\
\hline BIOINTA 1005 & $\mathrm{C}$ & BAJA & MSMR & 1 \\
\hline
\end{tabular}

Referencias: $\mathrm{MR}=$ moderadamente resistente, $\mathrm{MS}=$ moderadamente susceptible, $\mathrm{S}=$ susceptible, $\mathrm{MSMR}=$ de moderadamente susceptible a moderadamente resistente. $\mathrm{L}=$ largo, $\mathrm{C}=$ corto.

malezas como Cynodon dactylon (L.) Pers. y en menor densidad sobre maíz, trigo, avena y soja (Remes Lenicov \& Virla, 1999). Esta especie también ha sido citada como vectora natural de otro rhabdovirus Cynodon chlorotic streak en otros países (Nault \& Ammar, 1989). Esta situación sugiere que T. propinqua podría actuar como vectora natural del BYSMV en Argentina, más aún si se considera que esta especie mantiene su nivel poblacional durante todo el año, mientras que otros delfácidos disminuyen sus poblaciones a niveles mínimos en época invernal, período donde BYSMV ha sido encontrado con alta incidencia. Por otra parte los insectos no sólo actúan como vectores sino que también son hospedantes para la replicación del virus, constituyendo así importantes reservorios del virus.

Por otro lado, se ha comprobado la capacidad vectora natural de D. kuscheli para transmitir BYSMV en Argentina, siendo este el primer reporte que identifica a esta especie como vectora de otras virosis además del Mal de Río Cuarto virus (MRCV) (Ornaghi et al., 1999). En Argentina, este delfácido se encuentra frecuentemente asociado a los cultivos de avena, centeno, maíz y trigo y a las gramíneas que los rodean (Remes Lenicov \& Virla, 1999), siendo la avena uno de los hospedantes invernales preferenciales en donde se alimenta y reproduce esta especie (Remes Lenicov et al., 1991).
En Argentina, el BYSMV fue detectado en infecciones naturales en cultivos de trigo durante la campaña 2006. Sin embargo, se demostró que avena y cebada, especies que experimentalmente habían evidenciado síntomas característicos de la enfermedad también resultaron ser hospedantes naturales del virus. Estos resultados, coinciden con los reportados por otros investigadores, quienes detectaron infecciones naturales de BYSMV en avena, cebada y triticale en otras partes del mundo (Conti, 1980; Makkouk et al., 1996; Makkouk et al., 2001). En Argentina, hasta el momento BYSMV no se ha detectado en triticale en infecciones naturales aunque fue posible transmitirlo experimentalmente con D. kuscheli, por lo que se estima que este cereal también puede actuar como hospedante natural del virus. Por otra parte, se ha identificado a BYSMV en sorgo y cebadilla criolla infectados naturalmente, pero no así en centeno, hasta el momento. Al respecto, Conti (1980) evaluando el rango de hospedantes del BYSMV detectado en el norte de Italia, encontró que el virus se transmite experimentalmente con Laodelphax striatellus a varias especies de Bromus, a sorgo (Sorghum halepense, S. vulgare) y también a centeno, por lo que esta última especie también podría actuar como reservorio natural en Argentina. La persistencia de un virus en el ambiente y su habilidad 
Identificación y caracterización biológica del Barley yellow striate mosaic virus (BYSMV): Nueva...

para causar enfermedades en los cultivos anuales se ve incrementada con la presencia de los hospedantes o reservorios de invierno. Así, el conocimiento del rango de plantas hospedantes es importante para comprender la epidemiología de la enfermedad. Este rango, además es utilizado para propósitos de diagnóstico y reconocimiento de entre especies de virus (Watson \& Gibbs, 1974).

En Argentina, la sintomatología expresada por cada especie durante este estudio, concuerda con la descripta por Conti (1980), con la excepción del enrojecimiento en las hojas basales que este autor observó en la avena cv. Alba, lo que podría depender del cultivar utilizado en los ensayos por este autor.

Considerando que los resultados obtenidos en la evaluación de la patogenicidad entre los aislamientos de BYSMV de Argentina no mostraron diferencias, resulta de especial interés profundizar este tipo de estudios, como por ejemplo conocer las concentraciones virales que pueden alcanzarse en los tejidos de las plantas de las diferentes especies y caracterizar molecularmente los aislamientos (Conci, 1999).

Con respecto a la evaluación de cultivares, la mayoría de ellos resultaron susceptibles al BYSMV. El hecho de que los cultivares sembrados posean diferentes ciclos vegetativos-reproductivos, sumado a que la fecha de siembra estuvo fuera de la estación normal pudo llevar a que algunos cultivares hayan sido más afectados que otros por las condiciones ambientales presentes en dicho ensayo o por la presión de inóculo dada en ese momento. Por el contrario, el cultivar Buck 75 Aniversario mostró una clara resistencia a la infección por BYSMV, lo que permitirá su empleo como posible estrategia de manejo para esta virosis, además de la eliminación de malezas aledañas a los lotes sembrados y otras especies susceptibles de crecimiento espontáneo.

Este constituye el primer reporte del BYSMV para el cultivo de trigo y otros cereales en la Argentina.

\section{REFERENCIAS BIBLIOGRAFICAS}

Conci V (1999) Técnicas Serológicas. In: Docampo D, Lenardon $\mathrm{S}$ (Eds.) Métodos para detectar patógenos sistémicos. Córdoba Argentina. IFFIVE (INTA)-JICA. pp. 23-39.

Conti M (1980) Vector relationship and other characteristics of barley yellow striate mosaic virus (BYSMV). Annals of Applied Biology 95:83-92.

Conti M, Plumb RT (1977) Barley yellow striate mosaic virus in the salivary glands in Planthopper Laodelphax striatellus Fallen. Journal of General Virology 34:107-114.

Falk BW, Tsai JH (1985) Serological detection and evidence for multiplication of maize mosaic virus in planthopper, Peregrinus maidis. Phytopathology 75:852-855.

Hogenhout S, Redinbaugh M, Ammar ED (2003) Plant and animal rhabdovirus host range: A bug's view. Trends in Microbiology 11:264-270.
Hogenhout SA, Ammar ED, Whitfield AE, Redinbaugh MG (2008) Insect vector interactions with persistently transmitted viruses. Annual Review of Phytopathology 46:327-359.

Jackson AO, Dietzgen RD, Goodin MM, Bragg JN, Deng M (2005) Biology of plant rhabdoviruses. Annual Reviews of Phytopathology 43:623-660.

Kondo H, Maeda T, Shirako Y, Tamada T (2006) Orchid fleck virus is a rhabdovirus with an unusual bipartite genome. Journal of General Virology 87:2413-2421.

Lockhart BEL, El-Maataoui, M, Carrol, TW, Lennon AM, Zaske SK (1986) Identification of barley yellow striate mosaic virus in Morocco and its field detection by enzyme immune assay. Plant Disease 70:1113-1117.

MAGYP (2011) http://www.minagri.gob.ar/SAGPyA/ (Acesso em 5 de Julio de 2011).

Makkouk KM, Bertschinger L, Conti M, Bolat N, Dusunceli F (1996) Barley yellow striate mosaic rhabdovirus naturally infects cereal crops in the Anatolian Plateau of Turkey. Journal of Phytopathology 144:413-415.

Makkouk KM, Ghulam W, Kumari SG (2001) First report of Barley yellow striate mosaic virus infecting barley and wheat in Lebanon. Plant Disease 84:446.

Mayo MA, Pringle CR (1998) Virus Taxonomy - 1997. Journal of General Virology 79:649-697.

Milne RG, Conti M (1986) Barley yellow striate mosaic virus. CMI/AAB Descriptions of Plant Viruses, v. 312. Kew UK. Association of Applied Biologists.

Milne RG, Maseng V, Conti M (1986) Serological relationships between the nucleocapsids of some planthopper-borne rhabdoviruses of cereals. Intervirology 25:86-87.

Minskaya LA, Fedotina VL, Borodina EE, Krylov AV (1987) Rhabdovirusy zlakov SSSR (Cereal rhabdoviruses in the USSR). Moscow USSR. Nauka.

Nault L, Ammar ED (1989) Leafhopper and planthopper transmission of plant viruses. Annual Review of Entomology 34:503-529.

Ornaghi JA, March GJ, Boito GT, Marinelli A, Beviacqua JE (1999) Infectivity in natural populations of Delphacodes kuscheli vector of Mal de Río Cuarto virus. Maydica 44:219-223.

PRECOPINTA (2011) http://www.inta.gov.ar/manfredi/info/ precop/gace_prensa010/cosecha_trigo_2010.htm. (Accesso em Junio 5, 2011).

Redinbaugh MG, Seifers DL, Meulia T, Abt JJ, Anderson RJ, Styer WE, Ackerman J, Salomon R, Houghton W, Creamer R, Gordon DT, Hogenhout SA (2002) Maize fine streak virus, a new leafhopper-transmitted rhabdovirus. Phytopatology 92:11671174.

Remes-Lenicov AMM, Virla E (1999) Delfácidos asociados al cultivo de maíz en la República Argentina (Insecta-HomopteraDelphacidae). Revista de la Facultad de Agronomía de La Plata 104:1-15.

Remes-Lenicov AMM, Virla E, Dagoberto E (1991) Cambios estacionales en la población del vector del "Mal de Río Cuarto" del maíz (Delphacodes kuscheli Fennah, 1955) en cultivos de avena y sus malezas circundantes en Sampacho, Córdoba. (InsectaHomoptera-Fulgoroidea). Taller de Actualización sobre Mal de 
Río Cuarto. Córdoba Argentina. INTA - CIMMYT. p. 116-129.

Sagadin M, Hunzincker H, Truol G (2007) Determinación de los agentes causales de una nueva sintomatología viral afectando trigo en Argentina. Fitopatologia Brasileira 32 (Supl): S 249. (Abstract)

Shtein-Margolina VA (2002) Cytopathology of plants infected with viruses. Ultraestructure of the leaf cells of cereals affected by cereal rhabdoviruses. Biological Bulletin 29:12-23.

Tordo N, Benmansour A, Calisher C, Dietzgen RG, Fang RX, Jackson AO, Kurath G, Nadin-Davis S, Tesh RB, Walker PJ (2005) Family Rhabdoviridae. In: Fauquet CM, Mayo MA, Maniloff J, Desselberger U, Ball LA (Eds.) Virus taxonomy. VIII Report of the International Commitee on Taxonomy of Viruses. Oxford UK. Elsevier Academic Press. pp. 623-644.

Truol G (2009) Enfermedades virales asociadas al cultivo de trigo en Argentina: Reconocimiento, importancia, formas de transmisión y manejo. Córdoba Argentina. INTA.

Truol G, Nome C, Sagadin M, Alemandri V, Conci V, Cafrune E (2009) Microscopía electrónica: Principios fundamentales, técnicas de microscopía electrónica empleadas en la identificación de virus de plantas. In: Laguna I, Conci V, Rodríguez Pardina P, Truol G, Firona M, DiFeo L (Eds.) Procedimientos empleados en la identificación de organismos fitopatógenos. Córdoba Argentina. Ediciones INTA. pp. 25-30.

Truol G, Sagadin MB, Bainotti CT (2008) Nueva enfermedad viral en el cultivo de trigo (Rhabdoviridae- Cytorhabdovirus). VII Congreso Nacional de Trigo. La Pampa Argentina. Ediciones INTA. p. PV-12.

Truol GA, Usugi T, Hirao J, Arneodo J, Giménez-Pecci MP, Laguna I (2001) Transmisión experimental del virus del mal de Río Cuarto (MRCV) por Delphacodes kuscheli. Fitopatología Brasileira 26:39-44.

USDA (2011) http://www.fas.usda.gov/psdonline/ (Acesso em Julio 5, 2011).

Watson L, Gibbs AJ (1974) Taxonomic patterns in host ranges of viruses among grasses, and suggestions on generic sampling for host-range studies. Annals of Applied Biology 77:23-32.

Zadoks JC, Chang TT, Konzak F (1974) A decimal code for the growth stages of cereals. Weed Research 14:415-421. 